
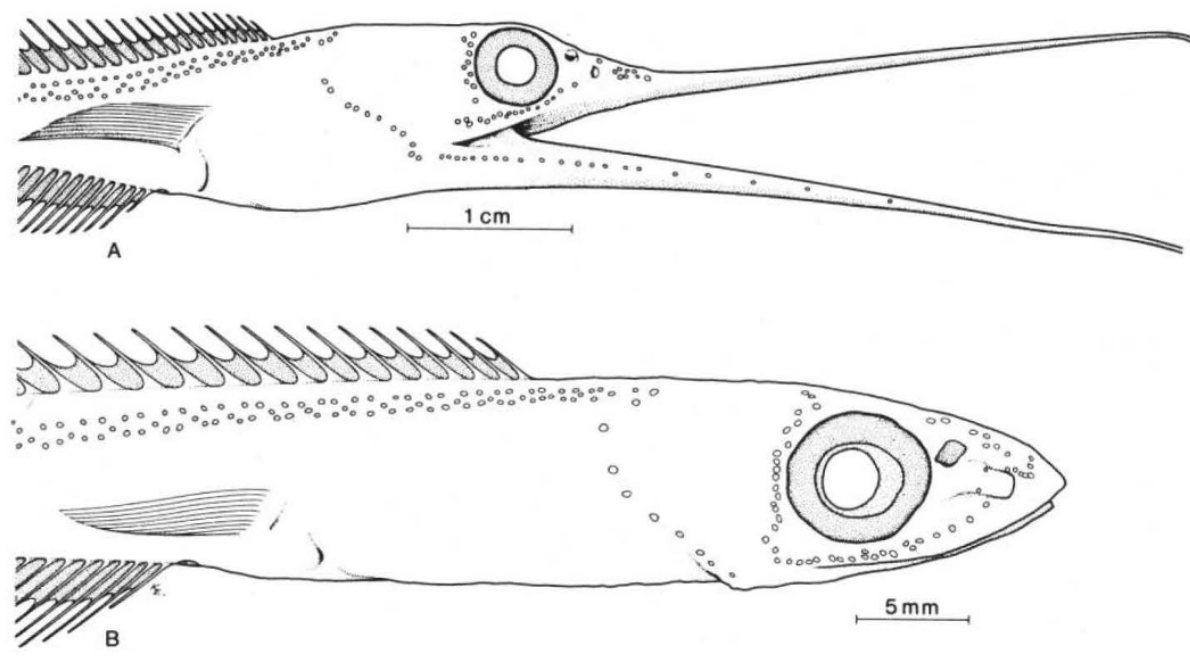

Head of Nemichthys scolopaceus: A, ; B, ripe $\delta^{\star}$.

\section{Snipe-eels unravelled}

from a Correspondent

THE snipe-eels are a family of eels found in mid-water in deep sea throughout all the temperate and tropical oceans. They derive their common name from the extraordinary elongation of the jaws which resemble a snipe's bill, except that the tips curve outwards in the vertical plane. In common with almost all groups of eels there has been much confusion in the nomenclature and systematic arrangement of the group although for several reasons the snipe-eels have been exceptionally complicated. A recent study by J. G. Nielsen and D. G. Smith on the eel family Nemichthyidae (DanaReport No. 88, 1; 1978) will, however, go a long way to clearing up the confusion in these fishes.

One of the problems with these eels is that they live in mid-water and until the development of effective mid-water nets in the middle of the present century, most of the specimens seen by naturalists were accidental captures made while hauling bottom trawls. Indeed, it is not infrequent for deepwater fishermen to find snipe-eels entangled by their slender 'beaks' in the wings of a bottom trawl. Most of the specimens described by early ichthyologists were thus isolated captures and often not in good condition (Nemichthys scolopaceus grows up to $1 \mathrm{~m}$ in length, is about $2 \mathrm{~cm}$ deep at its deepest part, and less than $1 \mathrm{~cm}$ wide-so general fragility might be expected). Another potent source of confusion arose from this fragility, such as when one species was described as new to science on the grounds that there was a ridge of skin on the dorsal surface of the snout-a feature which Nielsen and Smith show to be due to shrinkage of the skin. These and other factors all lead to a thorough con- fusion within the family, and it seems from the historical account of Nielsen and Smith that the group was fated to attract workers who failed to appreciate critical differences and even similarities. Since 1848, when the first genus Nemichthys was described, no fewer than eleven other genera have been proposed in the family, and the plurality of species has been even greater. In the current revision this has been reduced to three genera; only nine species are recognised.

A major factor in the artificial boost in the number of species was that mature male snipe-eels look totally dissimilar to females and immature fish. This sexual dimorphism was demonstrated by Smith and Nielsen (Steenstrupia 4 (1), 1; 1976) in a preliminary note, but the phenomenon is discussed in greater detail in their current revision. At sexual maturity male snipe-eels lose the characteristic snipe-bill, lose their teeth in the process, develop tubular anterior nostrils, change colour, and their pectoral fins move posteriorwards. Sexually mature females may also change colour and partially lose their teeth. So great are the differences between males and females that for over 50 years they have been placed in separate genera, and by some workers even in separate families and suborders!

It seems probable that the males at least spawn once and die soon after. The scarcity of short-nosed snipe-eels in collections suggests that they are rare in nature. However, as Nielsen and Smith point out, fishing gear may select in favour of the females, which having teeth and long snouts are more likely to become tangled in netting than are the toothless, short-snouted males. No doubt their study will stimulate further investigation of the ratio of male to female snipe-eels.

The fascinating shape of the jaws is briefly discussed but no new light is shed on the means by which these fish capture their food, which is mainly crustacean. An earlier suggestion by G. W. Mead and S. A. Earle (Proc. Calif. Acad. Sci. 38 (5), 99; 1970) was that the long, tooth-studded nonocclusible jaws might be used to entangle the antennae of the sergested and hoplophorid shrimps which they eat. The backward-pointing teeth would ensure that any trapped animal could only move towards the gullet, and yet the awkward divergence of the upper and lower jaws hardly seems to be an efficient method of capturing food.

Nielsen and Smith's study is a major advance in clarifying the confusion in taxonomy of the snipe-eels, but it is unfortunate that it appeared at almost the same time as the publication of a study by E. S. Karmowskaya (Trudy Inst. Okeanol. 109, 186-210; 1977) on the taxonomy and distribution of the genus Borodinula, with the description of a new species. Nielsen and Smith refer to this paper in a postscript added in proof, pointing out that Karmowskaya's new species is a species they consider was described as long ago as 1916, while Borodinula is a synonym of Avocetina. Evidently the era of confusion in snipe-eels is not yet over.

\section{Equatorial upwelling rates}

from M. Tomczak Jr.

Estimates of vertical velocities in the ocean have long been a matter of interest in oceanic science since the supply of nutrients for the surface layer where primary production through photosynthesis can take piace, almost exclusively depends on renewal from below. Apart from the important coastal upwelling regions along the coasts of California, Peru, North-west and South-west Africa, there is clear evidence for strong upwelling caused by a divergence in the surface layer flow along the Equator. To estimate the productivity of the region, however, is difficult because upwelling rates, that is, the amount of water which upwells into the surface layer per unit time interval cannot at present be measured directly. Average vertical velocities are believed to be of the order of a few centimetres per day or less.

Theoretical estimates of upwelling rates are usually based on the calculation of 'Ekman layer suction', the amount of water absorbed into the surface layer from below in order to compensate for local losses due to divergences in the surface currents. Since surface currents are wind-driven it is possible to calculate this effect 